\title{
Posterior Chamber Toric Implantable Collamer Lenses - Literature Review
}

\author{
Erik L. Mertens \\ Medipolis Eye Centre, Antwerp, \\ Belgium
}

\section{Introduction}

Posterior Chamber Phakic Toric Implantable Collamer Lenses have become increasingly used to correct refractive error associated with astigmatism. These devices are claimed to provide high efficacy in terms of refractive correction. This book chapter is an updated review on the safety and effectiveness and potential complications of the toric implantable collamer lens (Toric ICL) published in peer-review literature.

Toric implantable collamer lens (Toric ICL) from Staar Surgical Inc., Monrovia, CA, is a posterior chamber phakic intraocular lens that has been demonstrated to provide safe, effective, predictable and stable visual and refractive outcomes among various refractive ranges of ammetropia1-4. The present review will focus on the use of Toric ICL in the treatment of myopic astigmatism in normal eyes as well as in eyes with keratoconus, pellucid marginal degeneration, after keratoplasty, and also as a secondary piggyback lens.

\section{Toric ICL in normal astigmatic eyes}

The clinical outcomes of the U.S. FDA TICL clinical trial ${ }^{5}$ has been published supporting the efficacy and predictability of the TICL in the treatment of myopic astigmatism up to -4.00 diopters (D). In this study, two hundred ten eyes of 124 patients with pre-operative myopia between 2.38 and $19.5 \mathrm{D}$ (spherical equivalent) and 1 to $4 \mathrm{D}$ of astigmatism were enrolled. They analyzed the uncorrected visual acuity (UCVA), refraction, best spectacle-corrected visual acuity (BSCVA), adverse events, and postoperative complications. At 12 months postoperatively, the proportion of eyes with $20 / 20$ or better UCVA $(83.1 \%)$ was identical to the proportion of eyes with preoperative $20 / 20$ or better BCVA $(83.1 \%)$; $76.5 \%$ had postoperative BCVA better than or equal to preoperative BCVA. The mean manifest refractive cylinder dropped from $1.93 \pm 0.84$ at baseline to $0.51 \pm 0.48 \mathrm{D}$ postoperatively, a $73.6 \%$ decrease in astigmatism. Mean spherical equivalent refraction improved from $9.36 \pm 2.66 \mathrm{D}$ preoperatively to $0.05 \pm 0.46 \mathrm{D}$ postoperatively. A total of $76.9 \%$ of eyes were predicted accurately to within $\pm 0.5 \mathrm{D}, 97.3 \%$ to within $\pm 1.0 \mathrm{D}$, and $100 \%$ to within $\pm 2.0 \mathrm{D}$ of predicted spherical equivalent. Postoperatively, $37.6 \%$ of eyes had a BCVA of 20/12.5 or better, compared with a preoperative level of $4.8 \%$. BCVA of 20/20 or better occurred in $96.8 \%$ postoperatively, compared with $83.1 \%$ preoperatively. Mean improvement in BCVA was 0.88 lines; there were 3 cases $(1.6 \%)$ that lost $\geq 2$ lines of BCVA, whereas $18.9 \%$ of cases improved by $\geq 2$ lines. A total of $76.4 \%$ of cases gained $\geq 1$ lines of BCVA, whereas only $7.5 \%$ 
of cases lost the equivalent amount (Fig. 1). Three ICL removals were performed without significant loss of BCVA, and 1 clinically significant-lens opacity was observed. They concluded that their results support the efficacy and predictability of Toric ICL implantation to treat moderate to high myopic astigmatism, without identifying important safety concerns during the follow-up.

\section{Sanders et al · FDA Clinical Trial of the Toric ICL for Myopic Astigmatism}

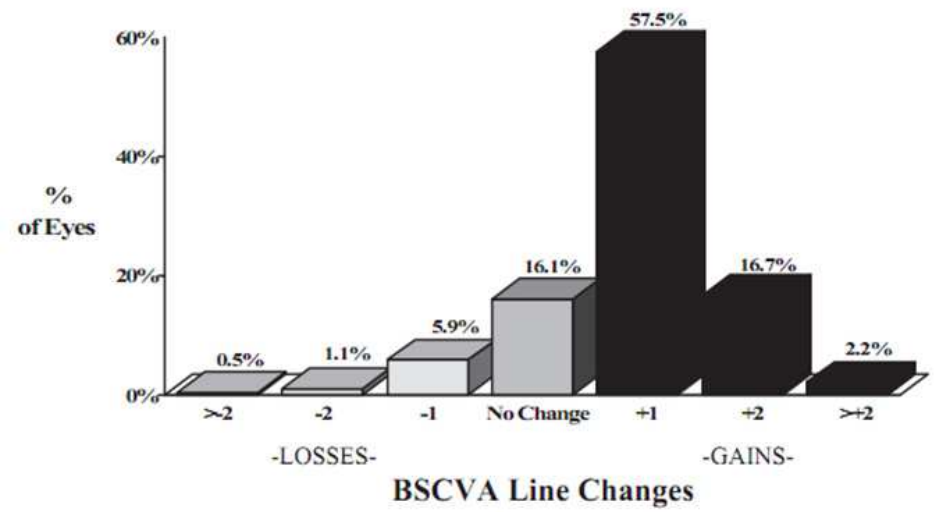

Fig. 1. Safety: Changes in Lines of vision (BCVA) before and after 12 months of Toric ICL Implantation

Kamiya et al. ${ }^{6}$ have also analyzed the outcomes of the Toric ICL being compared with wavefront-guided laser in situ keratomileusis (LASIK) in high myopic astigmatism. They studied 30 eyes (18 patients) having Toric ICL implantation and 24 eyes (17 patients) having wavefront-guided LASIK (Technolas 217z) to correct high myopic astigmatism (spherical equivalent $\leq-6.0 \mathrm{D}$; refractive cylinder $\mathrm{r} \geq 1.0 \mathrm{D}$ ). At 6 months, the mean safety index was $1.28 \pm 0.25$ in the Toric ICL group and $1.01 \pm 0.16$ in the LASIK group and the mean efficacy index, $0.87 \pm 0.15$ and $0.83 \pm 0.23$, respectively. All eyes in the Toric ICL group and $71 \%$ of eyes in the LASIK group were within $\pm 1.00 \mathrm{D}$ of the targeted spherical equivalent correction. The mean change in manifest refraction from 1 week to 6 months was $-0.04 \pm 0.24 \mathrm{D}$ in the Toric ICL group and $-0.60 \pm 0.49 \mathrm{D}$ in the LASIK group. There were no significant complications in the Toric ICL group; 2 eyes $(8.3 \%)$ in the LASIK group required enhancement ablations. They concluded that Toric ICL implantation was better than wavefront-guided LASIK in eyes with high myopic astigmatism in almost all measures of safety, efficacy, predictability, and stability, suggesting that Toric ICL implantation may become a viable surgical option to treat high myopic astigmatism.

Following a comparison from Kamiya et al. ${ }^{6}$, Choi et al. ${ }^{7}$ compared the results between Toric ICL and bioptics (ICL + excimer laser ablation) for the correction of myopic astigmatism. They performed a retrospective evaluation in 29 eyes (20 patients) with Toric ICL implantation and 26 eyes (17 patients) treated with bioptics. For eyes treated with bioptics, corneal ablation was performed at 1.5 to 5 months (mean 2.56 months) after ICL implantation by laser epithelial keratomileusis in 17 eyes, LASIK in 8 eyes, and photorefractive keratectomy in 1 eye. UCVA, BCVA, refraction, adverse events, safety, and 
efficacy were assessed preoperatively and 1, 6, and 12 months postoperatively. At 1 month postoperatively, UCVA in the Toric ICL group was significantly higher than in the bioptics group $(\mathrm{P}=.02)$. However, the difference in UCVA at 12 months was not significant. At 12 months, mean spherical equivalent refraction was $0.33 \pm 0.21 \mathrm{D}$ in the Toric ICL group and $0.29 \pm 0.41 \mathrm{D}$ in the bioptics group $(\mathrm{P}=.07)$. Mean astigmatic error was higher in the Toric ICL group $(-0.42 \pm 0.32 \mathrm{D})$ than in the bioptics group $(-0.32 \pm 0.38 \mathrm{D})(\mathrm{P}=.10)$. In the bioptics group, the mean refractive cylinder at 12 months decreased from that reported at 6 months because of retreatment performed in two eyes. Safety and efficacy were not statistically different between groups. One eye with a Toric ICL was treated to correct lens decentration and two crystalline lens opacities were observed after bioptics. They concluded that Toric ICL implantation provides reliable visual outcomes similar to bioptics and that the advantages of Toric ICL implantation are a more stable visual outcome and the elimination of laser treatments and their inherent risks.

Bhikoo et al. ${ }^{8}$ reported their outcomes at 12 -months follow-up in 77 eyes with moderate to high myopic astigmatism who underwent Toric ICL implantation. The preoperative mean spherical equivalent ranged from $-2.50 \mathrm{D}$ to $-15.00 \mathrm{D}$ of myopia and from $1.00 \mathrm{D}$ to $7.00 \mathrm{D}$ of astigmatism. At 12 months, mean manifest refractive cylinder decreased $81 \%$ from 2.38 $\mathrm{D}$ to $0.44 \mathrm{D}$. Mean manifest refractive cylinder within $1.00 \mathrm{D}$ occurred in $99 \%(76 / 77)$ of eyes, whereas $86 \%(66 / 77)$ was within 0.75 D. $99 \%(76 / 77)$ had postoperative BCVA better than or equal to preoperative values, whereas $78 \%(60 / 77)$ gained up to one line BCVA and $1 \%(1 / 77)$ lost one line BCVA. Uncorrected binocular vision of $6 / 6$ or better occurred in $90 \%(38 / 42)$ of patients compared with binocular BCVA of $6 / 6$ or better in $67 \%(28 / 42)$ preoperatively. One ICL was replaced due to low vaulting and two eyes with astigmatism of 3.25 D and 3.50 D received subsequent LASIK to reduce residual small refractive errors. Indications for ICL were: myopia too high for LASIK $(73 \%)$, cornea too thin for LASIK $(44 \%)$ and contact lens intolerance (33\%). Night halos were reported in $10 \%(8 / 77)$ of eyes at 12 months, one ICL was removed due to unrecognized preoperative glaucoma and there were no cases of cataract formation, or endophthalmitis. They concluded that the outcome supports the safety, efficacy and predictability of Toric ICLs to treat myopic astigmatism.

In a recent study, Kamiya et al. ${ }^{9}$ assessed the 1-year clinical outcomes of Toric ICL implantation for moderate to high myopic astigmatism in 56 eyes of 32 consecutive patients, with spherical equivalent errors of -4.00 to $-17.25 \mathrm{D}$ and cylindrical errors of -0.75 to $-4.00 \mathrm{D}$. They analyzed UCVA, BCVA, safety index, efficacy index, predictability, stability, adverse events and measured the higher order aberrations (HOAs) and the contrast sensitivity function. LogMAR UCVA and BCVA were $-0.11 \pm 0.12$ and $-0.19 \pm 0.081$ year after surgery, respectively. The safety and efficacy indices were $1.17 \pm 0.21$ and $1.00 \pm 0.29$ with $91 \%$ and $100 \%$ of the eyes within 0.5 and $1.0 \mathrm{D}$, respectively, of the targeted correction. Manifest refraction changes of $-0.07 \pm 0.27 \mathrm{D}$ occurred from 1 week to 1 year. For a 4 -mm pupil, fourthorder aberrations were changed, not significantly, from $0.05 \pm 0.02 \mu \mathrm{m}$ before surgery to $0.06 \pm 0.03 \mu \mathrm{m}$ after surgery $(\mathrm{P}=0.38$ ). Similarly, for a $6-\mathrm{mm}$ pupil, fourth-order aberrations were not significantly changed, merely from $0.20 \pm 0.08 \mu \mathrm{m}$ before surgery to $0.23 \pm 0.11 \mu \mathrm{m}$ after surgery $(P=0.15)$. The area under the log contrast sensitivity function was significantly increased from $1.41 \pm 0.15$ before surgery to $1.50 \pm 0.13$ after surgery $(\mathrm{P}<0.001)$. No visionthreatening complications occurred during the observation period. They concluded that in their experience, the Toric ICL performed well in correcting moderate to high myopic 
astigmatism during a 1-year observation period, suggesting its viability as a surgical option for the treatment of such eyes.

Alfonso et al. ${ }^{10}$ analyzed their outcomes with the lens in 55 eyes; assessment included UCVA, BCVA, refraction, vault and adverse events 12 months post-surgery. Preoperatively, the mean sphere in the 55 eyes was $-4.65 \pm 3.02 \mathrm{D}$ (range -0.50 to $-12.50 \mathrm{D}$ ) and the mean cylinder, $-3.03 \pm 0.79 \mathrm{D}$ (range -1.25 to $-4.00 \mathrm{D}$ ). At 12 months, the mean Snellen decimal UCVA was $0.80 \pm 0.20$ and the mean BCVA, $0.85 \pm 0.18 ; 62.0 \%$ of eyes had a BCVA of $20 / 20$. More than $50.0 \%$ of eyes gained 1 or more lines of BCVA. The treatment was highly predictable for spherical equivalent $\left(\mathrm{r}^{2}=0.99\right)$ and astigmatic components J0 $\left(\mathrm{r}^{2}=0.97\right)$ and $\mathrm{J} 45\left(\mathrm{r}^{2}=0.99\right)$. Of the eyes, $94.5 \%$ were within $\pm 0.50 \mathrm{D}$ of the attempted spherical equivalent and all were within $\pm 1.00 \mathrm{D}$. For J0, $94.5 \%$ of eyes were within $\pm 0.50 \mathrm{D}$ and for J45, $98.2 \%$ of eyes; all eyes were within $\pm 1.00 \mathrm{D}$. The efficacy index was 0.95 at 3 months and 1.08 at 1 year. They concluded that the UCVA and BCVA with the Toric ICL were good and highly stable over 12 months, confirming the procedure is safe, predictable, and effective for correction of moderate to high astigmatic. Similarly, they also analyzed the outcomes for eyes with preoperative cylinder values higher than $4.00 \mathrm{D}^{11}$. The study included 15 eyes of 12 patients (9 women). Preoperatively, the mean manifest spherical refraction was $-1.98 \mathrm{D} \pm 1.32$ (range -0.50 to $-5.50 \mathrm{D}$ ) and the mean refractive cylinder, $-4.85 \pm 0.83 \mathrm{D}$ (range -6.50 to -4.00 D). At 12 months, the mean refractive cylinder was $-0.55 \pm 0.52 \mathrm{D}$ (range -1.50 to $0.00 \mathrm{D}$ ), with $93.3 \%$ of eyes having less than $1.00 \mathrm{D}$ of cylinder. The mean spherical equivalent was $0.31 \pm 0.42$ (range -1.00 to $0.75 \mathrm{D}$ ), with more than $70 \%$ of eyes within $\pm 0.50 \mathrm{D}$ of the target. For the astigmatic components, $93.3 \%$ of eyes were within $\pm 1.00 \mathrm{D}$ of J0 $\left(\mathrm{r}^{2}=0.98\right)$ and all eyes were within $\pm 1.00 \mathrm{D}$ of $\mathrm{J} 45\left(\mathrm{r}^{2}=0.98\right)$. The mean UCVA was $0.70 \pm 0.20$ and the mean BCVA, $0.83 \pm 0.12$, bieng the overall efficacy index 0.90. Postoperatively, all eyes had unchanged BCVA or gained 1 or more lines. They consluded, that the refractive outcomes and improvement in UCVA and BCVA were rapidly achieved and remained fairly consistent throughout the follow-up period, supporting the use of TICL in eyes with high astigmatism.

In a recent paper, Mertens ${ }^{12}$ assessed the predictability, efficacy, safety and stability in patients who received a Toric ICL to correct moderate to high myopic astigmatism. He studied 43 eyes of 23 patients with a mean spherical refraction of $-4.98 \pm 3.49 \mathrm{D}$ (range: 0 to $-13 \mathrm{D}$ ), and a mean cylinder of $-2.62 \pm 0.97 \mathrm{D}$ (range: -1.00 to $-5.00 \mathrm{D}$ ). Main outcomes measures evaluated during a 12-month follow-up included UCVA, refraction, BCVA, vault, and adverse events. At 12 months the mean Snellen decimal UCVA was $0.87 \pm 0.27$ and mean BCVA was $0.94 \pm 0.21$, with an efficacy index of 1.05 . More than $60 \%$ of the eyes gained $\geq 1$ line of BCVA (17 eyes, safety index of 1.14). The treatment was highly predictable for spherical equivalent $\left(r^{2}=0.99\right)$ and astigmatic components: $\mathrm{J}_{0}\left(r^{2}=0.99\right)$ and $\mathrm{J}_{45}\left(r^{2}=0.90\right)$ (Fig.2). The mean spherical equivalent dropped from $-7.29 \pm 3.4 \mathrm{D}$ to $-0.17 \pm 0.40 \mathrm{D}$ at 12 months. Of the attempted spherical equivalent, $76.7 \%$ of the eyes were within $\pm 0.50 \mathrm{D}$ and $97.7 \%$ eyes were within $\pm 1.00 \mathrm{D}$, respectively. For $\mathrm{J}_{0}$ and $\mathrm{J}_{45}, 97.7 \%$ and $83.7 \%$ were within $\pm 0.50 \mathrm{D}$, respectively. He concluded that the outcomes of the study support the safety, efficacy, and predictability of Toric ICL implantation to treat moderate to high myopic astigmatism.

In addition, it should be considered that custom-designed Toric ICL may correct large sphero-cylindrical refractive errors. Mertens et al..$^{13}$ reported a case of a 40 -year-old woman with high astigmatism and thin corneas who underwent bilateral custom-designed Toric ICL implantation. The appropriate Toric ICL power was calculated to be $-8.00+8.00 \times 96^{\circ}$ for 


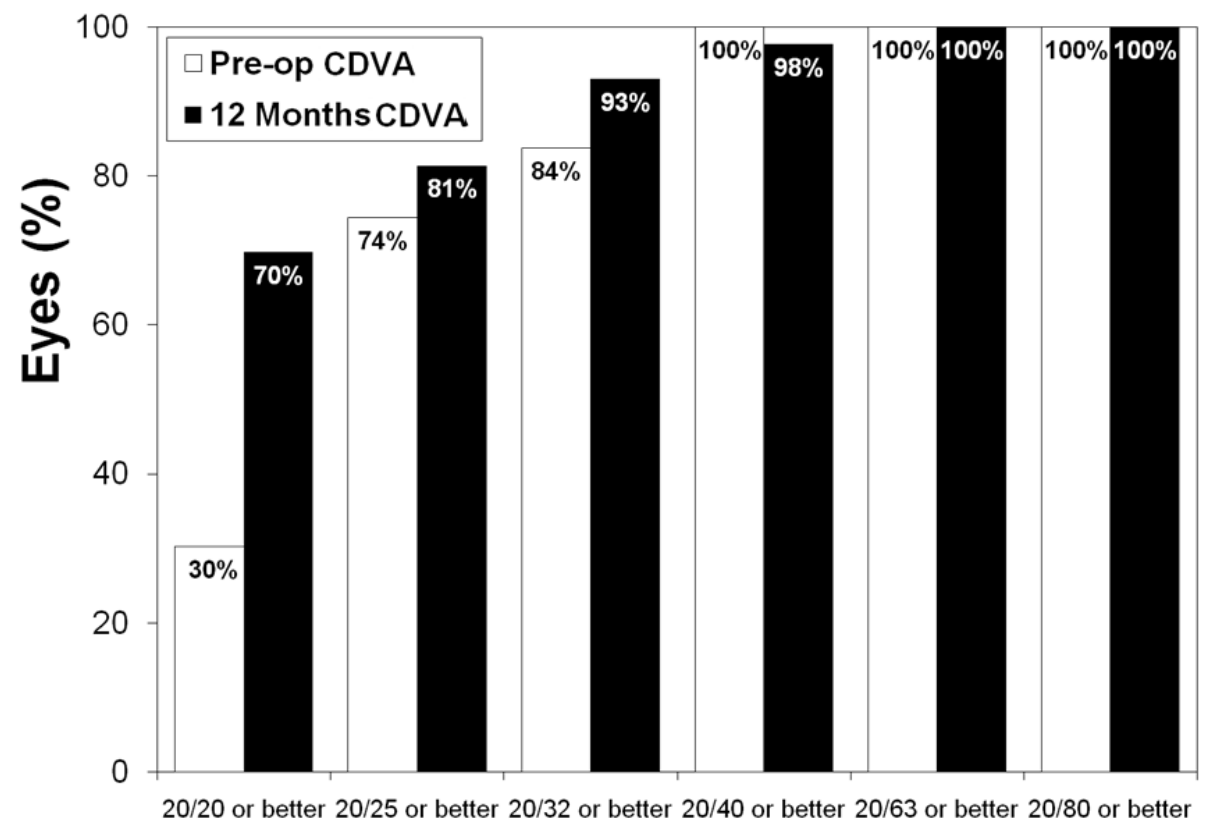

\section{Cumulative Snellen Visual Acuity}

Fig. 2. Preoperative versus 12 month postoperative best corrected visual acuity (BCVA) after Toric implantable collamer lens implantation. Clinical Ophthalmology 2011:5 369-375

the right eye and $-8.50+7.50 \times 86^{\circ}$ for the left eye with an optical zone of $5.5 \mathrm{~mm}$ and 6.875 $\mathrm{mm}$ at the corneal plane. Their results, at 3 and 6 months postoperatively, showed that UCVA and DCVA of both eyes improved to 20/20 and 20/16, respectively. At 19 months, UCVA was 20/20 and 20/16 in the right and left eyes, respectively, and BCVA had improved to $20 / 16$ and $20 / 10$, respectively. The subjective refraction was stable, with a change of $-0.37 \pm 0.17 \mathrm{D}$ from preoperative to 19 months postoperatively. Throughout the postoperative period, iridotomies remained patent and the corneas were clear. They concluded that bilateral implantation of the custom-designed Toric ICL successfully corrected the patient's high astigmatism. Preoperative subjective refractive cylinder of -5.25 $\times 6^{\circ}$ in the right eye and $-5 \times 176^{\circ}$ in the left eye changed to $-0.5 \times 77$ degrees and $-0.5 \times 115^{\circ}$, respectively, after Toric ICL implantation. There was almost no change in corneal astigmatism. This customized approach led to UCVA of 20/20 in the right eye and 20/16 in the left eye, and DCVA of 20/16 in the right eye and 20/10 in the left eye.

Mertens described the importance of preoperative marking of the eye's horizontal axis prior to Toric ICL implantation ${ }^{12-13}$ (Fig. 3). This axis would be the reference for later alignment of the lens to the target axis (Fig 4). When doing so intra-operatively, the surgeon must pay attention to use the entrance pupil as a reference for axis marking instead of the geometrical center of the cornea, thus avoiding undesired edge glare and induced coma and other secondary aberrations. Postoperatively, the vaulting of the Toric ICL can be easily assessed with the slit lamp (Fig. 5) 

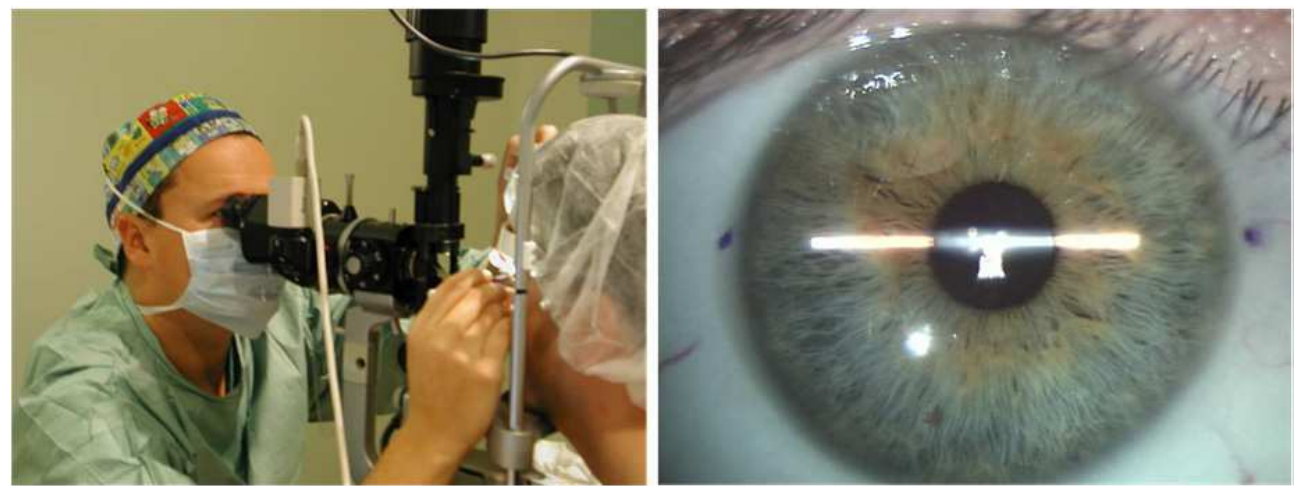

Fig. 3. Preoperative marking of the eye's horizontal axis prior to Toric ICL implantation

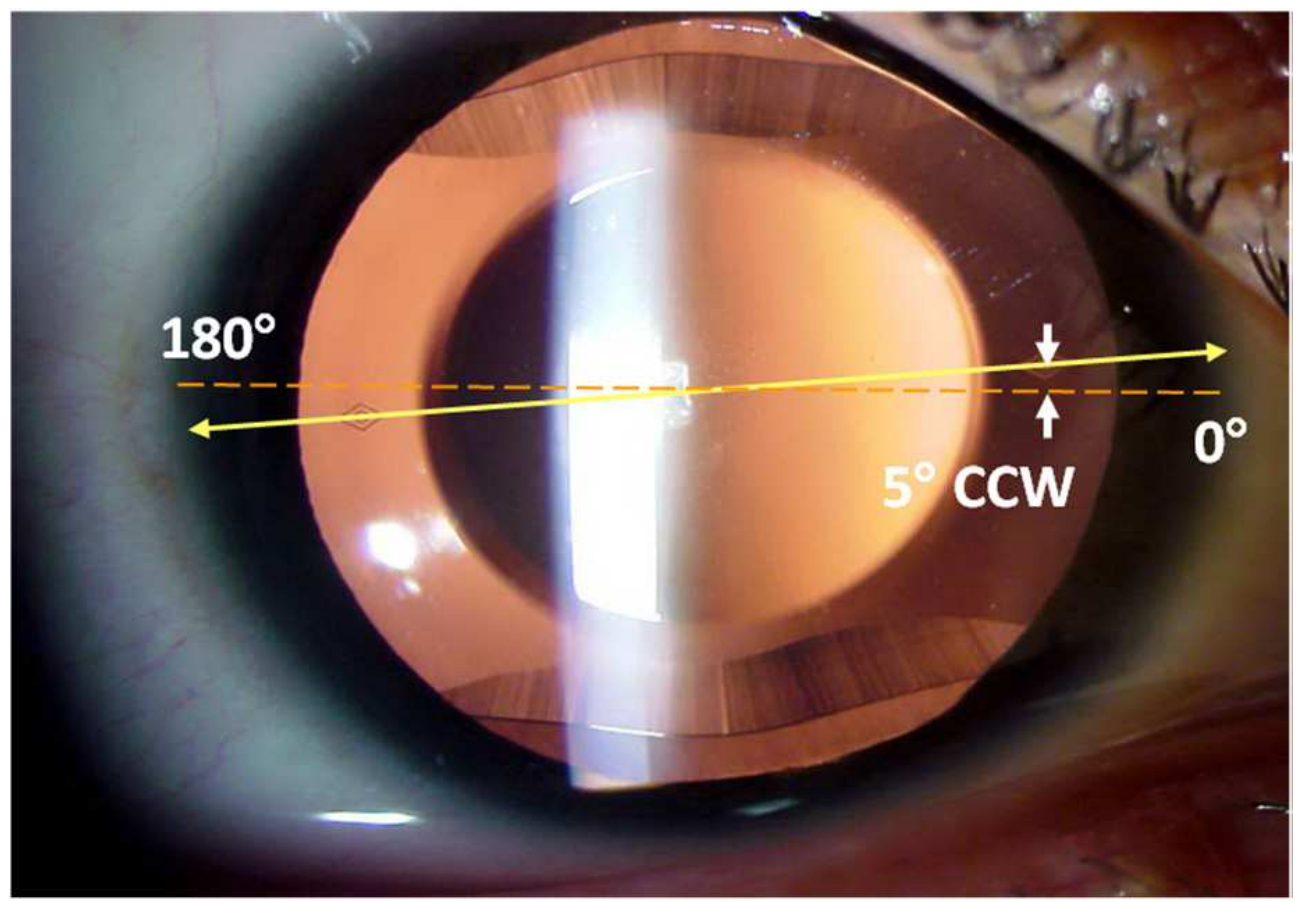

Fig. 4. Yellow line indicates lens horizontal axis connecting the 2 diamond-shaped marks of the Toric ICL. The arrows indicate that the surgeon aligned the lens at $5^{\circ} \mathrm{CCW}$ from the horizontal meridian.

\section{TICL in eyes with keratoconus}

In keratoconic eyes in which keratorefractive or other alternative refractive procedures were not a good or feasible option, Toric ICL implantation showed promising results. In this case, for example, Coskunseven et al. ${ }^{14}$ evaluated the results of combined Intacs (Addition 


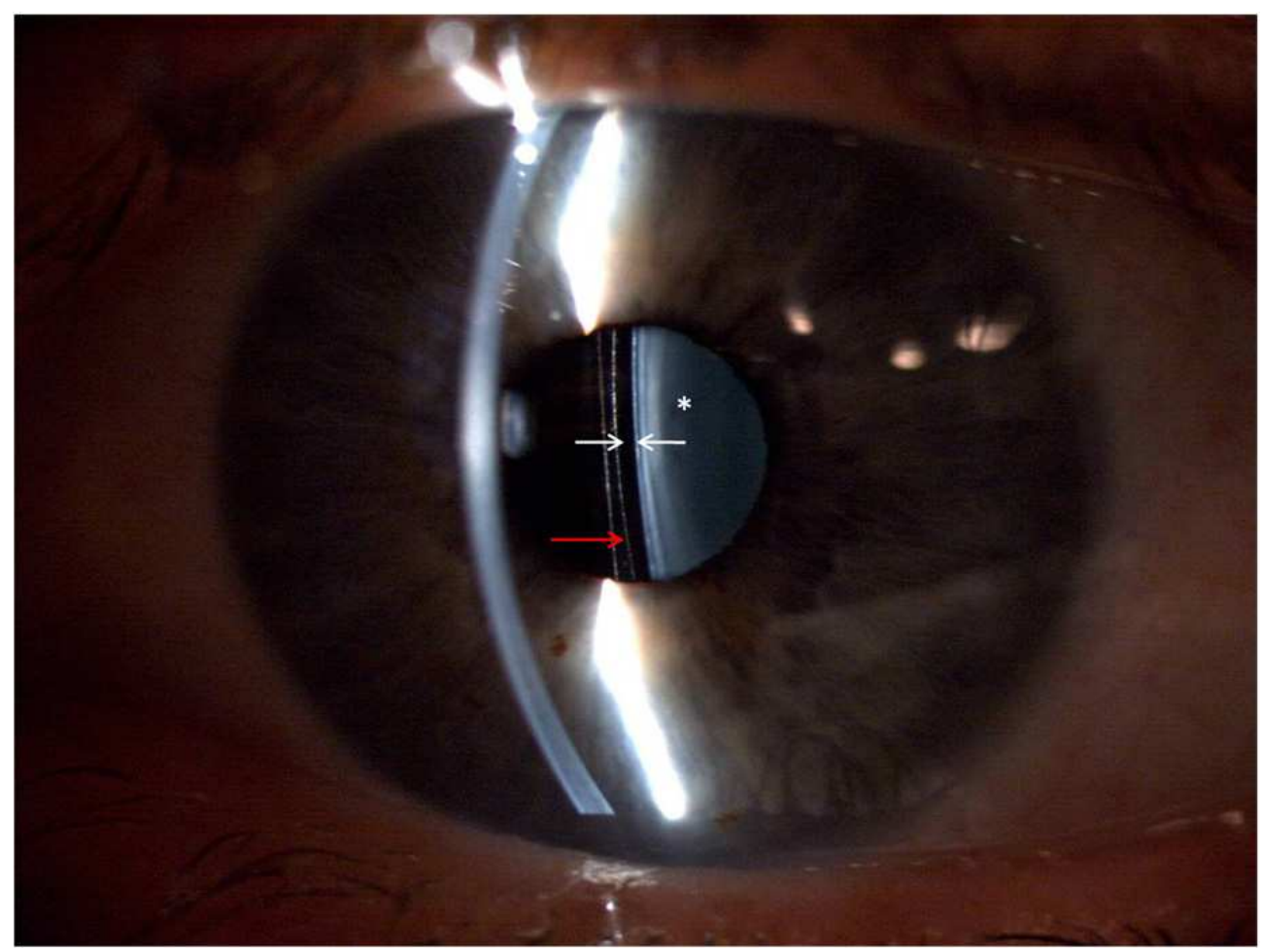

Fig. 5. Two white arrows: Clearance from the Toric ICL (red arrow) and the crystalline lens $\left(^{*}\right)$ is assessed with the slit-lamp. An optical section focused on the implant will allow the surgeon to observe the Toric ICL-lens space (vault).

Technology, Fremont, CA) and the TICL implantation in keratoconic patients with extreme myopia and irregular astigmatism. They reported the outcomes in three eyes of two consecutive highly myopic keratoconic patients who had undergone Toric ICL implantation after Intacs procedure. Implantation of the Toric ICLs was performed at intervals between six and 10 months after Intacs procedure. They did not encounter intraoperative or postoperative complications. An improvement in UCVA and DCVA was found after Intacs and TICL procedures in all eyes. All eyes were within $1 \mathrm{D}$ of emmetropia, whereas the mean manifest refractive spherical equivalent refraction decreased from $-18.50 \pm 2.61 \mathrm{D}$ (range, 16.75 to $-21.50 \mathrm{D}$ ) to $0.42 \mathrm{D}$ (range, 0 to $-0.75 \mathrm{D}$ ). The mean difference between preoperative and last follow-up UCVA and BCVA was a gain of 6.67 \pm 1.15 lines (ranging from six to eight lines) and $4.33 \pm 2.52$ lines (ranging fromof two to seven lines), respectively. They concluded that combined Intacs and Toric ICL implantation in a two-step procedure is an effective method for correcting keratoconic patients with extreme myopia.

Kamiya et al.15 showed two patients in whom Toric ICL have been effective for the correction of high myopic astigmatism with stable keratoconus. Both patients had a history of contact lens intolerance, and refraction and corneal topography were stable for 3 to 4 years. Preoperatively, the manifest refraction was $-10.00-6.00 \times 100^{\circ}$ in case 1 and $-8.00-2.75$ $\times 100^{\circ}$ in case 2 . Postoperatively, the manifest refraction was $+0.50-1.00 \times 90^{\circ}$ in case 1 and - 
$0.25-1.25 \times 100^{\circ}$ in case 2 . UCVA and BCVA were markedly improved after implantation in both patients without progressive sign of keratoconus during 1-year follow-up. They concluded that Toric ICL implantation may be an alternative for the correction of high myopic astigmatism in eyes with stable keratoconus. Recently, the authors have increased the sample size ${ }^{16}$. In a new study they evaluated 27 eyes of 14 patients with spherical equivalents of $-10.11 \pm 2.46 \mathrm{D}$ and astigmatism of $-3.03 \pm 1.58 \mathrm{D}$ who underwent Toric ICL implantation for mild keratoconus. LogMAR UCVA and LogMAR BCVA were $-0.09 \pm 0.16$ and $-0.15 \pm 0.09$ respectively, 6 months after surgery. The safety and efficacy indices were $1.12 \pm 0.18$ and $1.01 \pm 0.25$. At 6 months, $85 \%$ and $96 \%$ of the eyes were within \pm 0.5 and $\pm 1.0 \mathrm{D}$ respectively of the targeted correction. No vision-threatening complications occurred during the observation period. They again concluded that Toric ICL implantation was good in all measures of safety, efficacy, predictability, and stability for the correction of spherical and cylindrical errors in eyes with early keratoconus, suggesting its viability as a surgical option for the treatment of such eyes.

Alfonso et al. ${ }^{17}$ also implanted the Toric ICL in 30 keratoconic eyes (21 patients) with a mean myopia of $-5.38 \pm 3.26 \mathrm{D}$ (range -13.50 to $-0.63 \mathrm{D}$ ) and a mean cylinder of $-3.48 \pm 1.24 \mathrm{D}$ (range 1.75 to $-6.00 \mathrm{D})$. At 12 months, $86.7 \%$ of the eyes were within $\pm 0.50 \mathrm{D}$ of the attempted refraction and all eyes were within $\pm 1.00 \mathrm{D}$. For the astigmatic components J0 and J45, 83.3\% of eyes and $86.7 \%$ of eyes, respectively, were within $\pm 0.50 \mathrm{D}$. The mean Snellen UCVA was $0.81 \pm 0.20$ and the mean BCVA, $0.83 \pm 0.18$; BCVA was $20 / 40$ or better in 29 eyes $96.7 \%$ of eyes and $20 / 25$ or better in 22 eyes (73.3\%). No eyes lost more than 2 lines of BCVA; 29 eyes (96.7\%) maintained or gained 1 or more lines being the efficacy index of 1.07 and the safety index, 1.16. There were no complications or adverse events concluding that Toric ICL implantation is a predictable, effective procedure to correct ametropia in eyes with keratoconus.

\section{Toric ICL after penetrating keratoplasty}

The use of the Toric ICL after penetrating keratoplasty has been also proposed. Alfonso et al. ${ }^{18}$, evaluated the efficacy, predictability, and safety of Toric ICL after this technique in 15 eyes that had preoperative myopia ranging from -2.00 to $-17.00 \mathrm{D}$ or astigmatism from -1.50 to -7.00 D. Twenty-four months postoperatively, the mean Snellen decimal UCVA was $0.51 \pm 0.30$. The UCVA was $20 / 40$ or better in 7 eyes $(46.6 \%)$ and the mean BCVA was $0.79 \pm 0.22$. The BCVA was $20 / 40$ or better in 12 eyes ( $80 \%)$ and $20 / 25$ in 6 eyes $(40 \%)$. No eye lost more than 1 line of acuity, 2 eyes gained 1 line, and 5 eyes gained more than 2 lines; 8 eyes were unchanged, being the safety index 1.58 . The spherical equivalent was within \pm 1.00 $\mathrm{D}$ in $80 \%$ of eyes and within $\pm 0.50 \mathrm{D}$ in $66.6 \%$ of eyes, with a mean postoperative value of $0.95 \pm 1.12 \mathrm{D}$. At 24 months, the mean endothelial cell loss was $8.1 \%$. they concluded that the results found indicate that Toric ICL is a viable treatment for myopia and astigmatism after penetrating keratoplasty in patients for whom glasses, contact lenses, or corneal refractive surgery are contraindicated.

A case report of Akcay et al. ${ }^{19}$ also adds valuable literature to this application. They describe that the patient's manifest refraction improved from $-8.0-1.75 \times 170^{\circ}$ preoperatively, with an UCVA of 0.15 and a BCVA of 0.4 , to $+0.75-0.50 \times 130^{\circ}$ postoperatively, with a UCVA of 0.8 and a BCVA of 1.0. No serious complications or refractive changes occurred during the 1year follow-up concludind that implantation of a myopic TICL in phakic eyes is an option to correct postkeratoplasty anisometropia and astigmatism. 


\section{Toric ICL in eyes with pellucid marginal degeneration}

Kamiya et al..$^{20}$ have also recently reported a case in which Toric ICL effectively corrected the refractive errors of pellucid marginal degeneration. They described preoperatively that, in the patient's right eye, the manifest refraction was $-10.5-3.5 \times 55^{\circ}$, the UCVA was 20/1000, and the BCVA was 20/16; in the left eye, the manifest refraction was $-11.0-6.5 \mathrm{x}$ $130^{\circ}$ and the UCVA and BCVA were 20/1000 and 20/20, respectively. After bilateral implantation of a TICL, in the right eye, the manifest refraction was $+1.50-0.75 \times 10^{\circ}$, the UCVA was 20/16, and the BCVA was 20/12.5; in the left eye, the manifest refraction was $+2.5-3.25 \times 125^{\circ}$ and the UCVA and BCVA were 20/40 and 20/16, respectively. They did not find signs of progressive disease and no vision-threatening complication were observed during the 6-months follow-up. They considered that Toric ICL implantation may be a viable surgical option for the correction of high myopic astigmatism in eyes with pellucid marginal degeneration.

\section{Toric ICL for secondary piggyback}

The last indication that has been considered for the use of Toric ICL is piggyback implantation. Kojima et al. ${ }^{21}$ investigated eight pseudophakic eyes of five patients who underwent piggyback insertion of a Toric ICL to correct residual refractive error. The results showed that pre- and 6-month postoperatively logMAR UCVA were $0.759 \pm 0.430$ and $0.201 \pm 0.458$, respectively, with all eyes within $\pm 0.50 \mathrm{D}$ of intended spherical equivalent refraction and refractive astigmatism within $\pm 0.50 \mathrm{D}$ in five $(62.5 \%)$ eyes and $\pm 1.00 \mathrm{D}$ in seven $(87.5 \%)$ eyes. No eyes lost more than one line of BCVA and pupillary block occurred in one eye on postoperative day 1 . They concluded that piggyback insertion of a Toric ICL appears to be effective and predictable in correcting refractive error in pseudophakic eyes.

\section{Complications and adverse events with Toric ICL}

Sanders et al. ${ }^{5}$ reported secondary surgical interventions in 5 eyes $(2.4 \%)$ in the Toric ICL study cohort. In 3 eyes the ICL was removed, in one case due to PI-related visual symptoms, in the second case due to trace anterior subcapsular opacity and in the last case due to oversizing and induced anisocoria. One eye had the ICL replaced with a smaller diameter ICL and another eye had a repositioning due to surgical misalignment.

In a more recent study, Kamiya $\mathrm{K}$ et $\mathrm{al}^{9}$ reported secondary surgical interventions in five eyes $(8.9 \%)$. These eyes required repositioning of the lens very early post-operatively, ranging from one day to one week due to off-axis alignment. Two eyes required late repositioning due to off-axis secondary to a traumatic event. Finally, three eyes developed asymptomatic subcapsular opacity, none of them requiring an ICL removal because there was no impact on BCVA. Otherwise they reported no cases on pigment dispersion, pupillary block or other vision-threatening complications during their follow-up period.

Reported adverse events related to Toric ICL are those applicable to ICL in addition to early surgical misalignment and rotation of the implant. Careful marking of the eye's axis and attention to marking the target axis are essential to ensure proper surgical alignment of the Toric ICL. Lens rotations may occur if the lens is too short for the eye's anatomy and in these cases an exchange for a longer diameter ICL should resolve the problem. In rare instances, an optimally vaulting lens may be found off-axis post-operatively; Navas et al ${ }^{22}$ found that 
repositioning of the lens back to target axis when the vault is optimal yield a satisfactory outcome in their case study.

Most common complications and adverse events reported with the ICL platform in general include: early replacements due to sizing issues (under- or over-sizing), lens repositioning (surgical misalignment or true early rotation, late rotation), development of anterior subcapsular opactity which becomes clinically significant requiring lens removal and cataract surgery, pupillary block and/or angle closure with elevated IOP due to non functioning peripheral iridotomies (PIs), (too small, too peripheral, occluded or narrowed), and to a lesser extent symptoms of glare/halos or lines coming from the peripheral iridotomies or from the smaller optical zone related to the patient's mesopic pupil diameter. Based on the meta-analysis from Chen et al. ${ }^{23}$ where different ICL lens designs were included (prototype and obsolete versions as well as currently available V4 model) the most common complication was cataract formation. Several factors involved in cataract development discussed in this analysis included age, degree of myopia, low vault, surgical trauma, learning curve, steroid use, lens design, pre-existing opacities, trauma and inflammation. Several other peer-reviewed articles support the relatively low incidence of complications with the ICL.

In conclusion, Toric ICL has been worldwide used for astigmatism correction showing their efficacy, predictability, stability and safety. Toric ICLs are considered an attractive approach, based in large part on the phenomenal acceptance of intraocular lenses for not only the aphakic or cataract patient but also, recently, the refractive patient. The present chapter reviewed the outcomes for normal astigmatic eyes and also those found in different keratoconic eyes, post-penetrating keratoplasty, eyes with pellucid marginal degeneration and also in pseudophakic eyes with the use ICL as secondary piggyback lens. In general terms, the results of Toric ICL implantation from these studies are in agreement confirming its predictability, efficacy, together with safety outcomes, making this option as a highly reliable alternative in the treatment of moderate to high astigmatism. Then, TICLs are safe and effective tools to compensate for different degrees of astigmatism, involving quite low risks.

\section{References}

[1] Sanders DR, Doney K, Poco M. United States Food and Drug Administration clinical trial of the Implantable Collamer Lens (ICL) for moderate to high myopia: three-year follow-up. Ophthalmology 2004;111:1683-1692.

[2] Uusitalo RJ, Aine E, Sen NH, Laatikainen L. Implantable contact lens for high myopia. J Cataract Refract Surg 2002;28:29-36.

[3] Lackner B, Pieh S, Schmidinger G et al. Long-term results of implantation of phakic posterior chamber intraocular lenses. J Cataract Refract Surg 2004;30:2269-2276.

[4] Pesando PM, Ghiringhello MP, Di MG, Fanton G. Posterior chamber phakic intraocular lens (ICL) for hyperopia: ten-year follow-up. J Cataract Refract Surg 2007;33:15791584.

[5] Sanders DR, Schneider D, Martin R et al. Toric Implantable Collamer Lens for moderate to high myopic astigmatism. Ophthalmology 2007;114:54-61.

[6] Kamiya K, Shimizu K, Igarashi A, Komatsu M. Comparison of Collamer toric implantable contact lens implantation and wavefront-guided laser in situ 
keratomileusis for high myopic astigmatism. J Cataract Refract Surg. 2008;34:168793

[7] Choi SH, Lee MO, Chung ES, Chung TY. Comparison of the toric implantable collamer lens and bioptics for myopic astigmatism. J Refract Surg. 2010;28:1-7

[8] Bhikoo R, Rayner S, Gray T. Toric implantable collamer lens for patients with moderate to severe myopic astigmatism: 12-month follow-up. Clin Experiment Ophthalmol 2010;38:467-74.

[9] Kamiya K, Shimizu K, Aizawa D, Igarashi A, Komatsu M, Nakamura A. One-year follow-up of posterior chamber toric phakic intraocular lens implantation for moderate to high myopic astigmatism. Ophthalmology 2010;117:2287-94

[10] Alfonso JF, Fernández-Vega L, Fernandes P, González-Méijome JM, Montés-Micó R. Collagen copolymer toric posterior chamber phakic intraocular lens for myopic astigmatism: one-year follow-up. J Cataract Refract Surg. 2010;36:568-76.

[11] Alfonso JF, Baamonde B, Madrid-Costa D, Fernandes P, Jorge J, Montés-Micó R. Collagen copolymer toric posterior chamber phakic intraocular lenses to correct high myopic astigmatism. J Cataract Refract Surg. 2010;36:1349-57.

[12] Mertens EL. Toric phakic implantable collamer lens for correction of astigmatism: 1year outcomes. Clinical Ophthalmology 2011:5 369-375

[13] Mertens EL, Sanders DR, Vitale PN. Custom-designed toric phakic intraocular lenses to correct high corneal astigmatism. J Refract Surg. 2008;24:501-6.

[14] Coskunseven E, Onder M, Kymionis GD, Diakonis VF, Arslan E, Tsiklis N, Bouzoukis DI, Pallikaris I. Combined Intacs and posterior chamber toric implantable Collamer lens implantation for keratoconic patients with extreme myopia. Am J Ophthalmol. 2007;144:387-389.

[15] Kamiya K, Shimizu K, Ando W, Asato Y, Fujisawa T. Phakic toric implantable collamer lens implantation for the correction of high myopic astigmatism in eyes with keratoconus. J Refract Surg. 2008;24:840-2

[16] Kamiya K, Shimizu K, Kobashi H, Komatsu M, Nakamura A, Nakamura T, Ichikawa K. Clinical outcomes of posterior chamber toric phakic intraocular lens implantation for the correction of high myopic astigmatism in eyes with keratoconus: 6-month follow-up. Graefes Arch Clin Exp Ophthalmol. 2010 Oct 16.

[17] Alfonso JF, Fernández-Vega L, Lisa C, Fernandes P, González-Méijome JM, MontésMicó R. Collagen copolymer toric posterior chamber phakic intraocular lens in eyes with keratoconus. J Cataract Refract Surg. 2010;36:906-16.

[18] Alfonso JF, Lisa C, Abdelhamid A, Montés-Micó R, Poo-López A, Ferrer-Blasco T. Posterior chamber phakic intraocular lenses after penetrating keratoplasty. J Cataract Refract Surg. 2009;35:1166-73.

[19] Akcay L, Kaplan AT, Kandemir B, Gunaydin NT, Dogan OK. Toric intraocular Collamer lens for high myopic astigmatism after penetrating keratoplasty. J Cataract Refract Surg. 2009;35:2161-3.

[20] Kamiya K, Shimizu K, Hikita F, Komatsu M. Posterior chamber toric phakic intraocular lens implantation for high myopic astigmatism in eyes with pellucid marginal degeneration. J Cataract Refract Surg. 2010;36:164-6. 
[21] Kojima T, Horai R, Hara S, Nakamura H, Nakamura T, Satoh Y, Ichikawa K. Correction of residual refractive error in pseudophakic eyes with the use of a secondary piggyback toric Implantable Collamer Lens. J Refract Surg. 2010;26:766-9.

[22] Navas A, Munoz-Ocampo M, Graue-Hernández E O., Gómez-Bastar A. Spontaneous rotation of a Toric Implantable Collamer Lens. Case Rep Ophthalmol 2010;1:99-104.

[23] Chen LJ, Chang YJ, Kuo JC, Rajagopal R, Azar DT. Metaanalysis of cataract development after phakic intraocular lens surgery. J Cataract Refract Surg 2008;34:1181-1200 


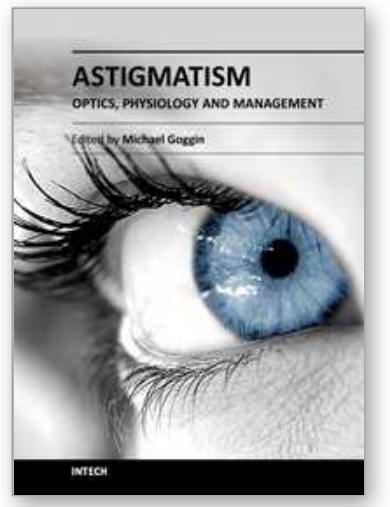

\author{
Astigmatism - Optics, Physiology and Management \\ Edited by Dr. Michael Goggin
}

ISBN 978-953-51-0230-4

Hard cover, 308 pages

Publisher InTech

Published online 29, February, 2012

Published in print edition February, 2012

This book explores the development, optics and physiology of astigmatism and places this knowledge in the context of modern management of this aspect of refractive error. It is written by, and aimed at, the astigmatism practitioner to assist in understanding astigmatism and its amelioration by optical and surgical techniques. It also addresses the integration of astigmatism management into the surgical approach to cataract and corneal disease including corneal transplantation.

\title{
How to reference
}

In order to correctly reference this scholarly work, feel free to copy and paste the following:

Erik L. Mertens (2012). Posterior Chamber Toric Implantable Collamer Lenses - Literature Review, Astigmatism - Optics, Physiology and Management, Dr. Michael Goggin (Ed.), ISBN: 978-953-51-0230-4, InTech, Available from: http://www.intechopen.com/books/astigmatism-optics-physiology-andmanagement/toric-posterior-chamber-phakic-implantable-collamer-lens-long-term-results

\section{INTECH}

open science | open minds

\section{InTech Europe}

University Campus STeP Ri

Slavka Krautzeka 83/A

51000 Rijeka, Croatia

Phone: +385 (51) 770447

Fax: +385 (51) 686166

www.intechopen.com

\section{InTech China}

Unit 405, Office Block, Hotel Equatorial Shanghai

No.65, Yan An Road (West), Shanghai, 200040, China

中国上海市延安西路65号上海国际贵都大饭店办公楼 405 单元

Phone: +86-21-62489820

Fax: $+86-21-62489821$ 
(C) 2012 The Author(s). Licensee IntechOpen. This is an open access article distributed under the terms of the Creative Commons Attribution 3.0 License, which permits unrestricted use, distribution, and reproduction in any medium, provided the original work is properly cited. 